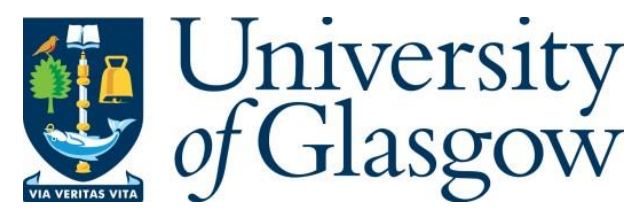

Carter, J. A. and Gordon, E. C. (2015) On cognitive and moral enhancement: a reply to Savulescu and Persson. Bioethics, 29(3), pp. 153-161.

There may be differences between this version and the published version. You are advised to consult the publisher's version if you wish to cite from it.

This is the peer reviewed version of the following article Carter, J. A. and Gordon, E. C. (2015) On cognitive and moral enhancement: a reply to Savulescu and Persson. Bioethics, 29(3), pp. 153-161, which has been published in final form at http://dx.doi.org/10.1111/bioe.12076. This article may be used for non-commercial purposes in accordance with Wiley Terms and Conditions for Self-Archiving.

http://eprints.gla.ac.uk/174178/

Deposited on: 27 November 2018

Enlighten - Research publications by members of the University of Glasgow http://eprints.gla.ac.uk 


\title{
On Cognitive and Moral Enhancement: A Reply to Savulescu and Persson
}

\author{
J. Adam Carter \& Emma C. Gordon \\ Edinburgh University
}

\begin{abstract}
In a series of recent works, Julian Savulescu and Ingmar Persson insist that, given the ease by which irreversible destruction is achievable by a morally wicked minority, (i) strictly cognitive bio-enhancement is currently too risky, while (ii) moral bioenhancement is plausibly morally mandatory (and urgently so). This paper aims to show that the proposal Savulescu \& Persson advance relies on several problematic assumptions about the separability of cognitive and moral enhancement as distinct aims. Specifically, we propose that the underpinnings of Savulescu's \& Persson's normative argument unravel once it is suitably clear how aiming to cognitively enhance an individual will in part require that one aim to bring about certain moral goods we show to be essential to cognitive flourishing; conversely, aiming to bring about moral enhancement in an individual must involve aiming to improve certain cognitive capacities we show to be essential to moral flourishing. After developing these points in some detail, and their implication for Savulescu's \& Persson's proposal, we conclude by outlining some positive suggestions.
\end{abstract}

\section{Background}

Julian Savulescu \& Ingmar Persson ${ }^{1}$ take as a starting point some relatively uncontroversial observations: firstly, that there are a minority of individuals whose objectives are to cause, for example, nuclear or biological destruction on a mass scale; secondly, that such irreversible devastation is much easier to cause than is any corresponding good that could ever offset such devastation. They reason that the increase of scientific knowledge achievable through cognitive enhancement accordingly threatens to speed up the path to humanity's destruction. Their injunction is that, in light of this doomsday risk, cognitive enhancement should not be pursued if not accompanied by moral enhancement, the latter which they take to be plausibly morally mandatory.

Moral bio-enhancement, though currently in its nascency, would involve (for instance) enhancing individuals' dispositions toward altruistic responses and sense of justice as fairness, perhaps by way of (for example) oxytocin ${ }^{2}$, SSRIs, Ritalin, propranolol, and genetic treatment ${ }^{3}$.

\footnotetext{
${ }^{1}$ See I. Persson \& J. Savulescu. The perils of Cognitive Enhancement and the Urgent Imperative to Enhance the Moral Character of Humanity. J Appl Philos 2008 25(3), and I. Persson \& J. Savulescu. 2012. Unfit for the Future: The Need for Moral Enhancement. Oxford: Oxford University Press for an expanded discussion. Cf. I. Persson \& J. Savulescu. Getting Moral Enhancement Right. Bioethics 2013 27:3: 124-131 for a reply to J. Harris. Moral Enhancement and Freedom. Bioetbics 2011: 25(2): 102-111, 107.

${ }^{2}$ Savulescu \& Persson discuss oxytocin's relationship with social behavior in J. Savulescu \& I. Persson. Moral Enhancement, Freedom and the God Machine. The Monist 2012 95(3): 399-421. Meanwhile, M. Kosfeld, et. al. Oxytocin Increases Trust in Humans. Nature 2005 435(7032): 673-6 links oxytocin with trust. ${ }^{3}$ Cf. T. Douglas. Moral Enhancement. J Appl Philos 2008 25(3): 228-245 on oxytocin and SSRIs. For more work on the most likely moral enhancers, see J. Shook. Neuroethics and the Possible Types of Moral
} 
Savulescu \& Persson's argument ${ }^{4}$ has already been challenged on several fronts. A sample of some notable criticisms include the following: that it is not obviously easier to cause great harm than great benefit ${ }^{5}$; that moral bio-enhancement undercuts human freedom ${ }^{6}$; that moral virtue is not biologically achievable ${ }^{7}$; that Savulescu \& Persson fail to appropriately consider non-authoritarian means of improving morality within a liberal democracy $^{8}$; that recent findings in moral psychology recommend more of a focus on traditional enhancement'; and that moral bioenhancement cannot be, in principle, adequately precise ${ }^{10}$.

While there is much to be said about all these criticisms, we will explore a strand of objection that is, comparatively, more fundamental, and which concerns the presuppositions of Savulescu's and Person's normative recommendations. Harris (2011) gestures toward this more fundamental issue in his remark that "there are good reasons to believe moral enhancement must, in a large part, consist of cognitive enhancement." However, if this is right, it seems that Savulescu \& Persson's argument leaves us with a kind of paradoxical dilemma, in so far as we are to take their recommendations seriously in practice. As Fenton (2010) astutely observes:

If we continue scientific research into non-traditional enhancement we are advancing the very body of knowledge that could prove to be our downfall, should the morally corrupt minority get their hands on it. But if we do not continue scientific research into enhancement, if we halt it out of concern for the consequences, then we have no hope of achieving the great moral progress that will ensure our survival of the species ${ }^{11}$.

With regard to cognitive enhancement, then, it seems we are (as Fenton puts it) in a kind of "damned if you do, damned if you don't" scenario ${ }^{12}$. If the stakes are as high as Savulescu \& Persson suggest, then this intractable dilemma would be more than an academic perplexity-it would be a grave practical hurdle.

\section{Sources of the Dilemma}

Enhancement. Am J Bioethics Neuroscience 2013 3 (4): 3-14. For the link between propranolol, negative biases and aversion to harming otherss, see Terbeck et. al. 2012. Propranolol reduces implicit negative racial bias. Psychopharmocology 222 (3): 419-24 and 2013. Beta adrenergic blockade reduces utilitarian judgement. Biol Psychol. 92 (2): 323-28.

${ }^{4}$ We are engaging primarily with the 2008 presentation of the argument. Savulescu \& Persson also make a plea for the urgency of moral enhancement in their 2012 (op. cit.) However, the case specifically against cognitive enhancement is made more sharply in the 2008 paper. Thanks to an anonymous referee for requesting clarification here.

${ }^{5}$ See Harris's counterexamples (2011), e.g. the eradication of smallpox and polio.

${ }^{6} \mathrm{~J}$. Harris, op. cit, 104-105. Inspired by Milton, Harris identifies one's "freedom to fall" as a precondition for autonomous action.

${ }^{7}$ Fröding, B.E.E. Cognitive Enhancement, Virtue Ethics and the Good Life. Neuroethics (2011) 4: 223-234.

${ }^{8}$ R. Joyce. Review of J. Savulescu \& I. Persson Unfit for the Future: The Need for Moral Enhancement. Analyis 2013: doi: 10.1093/analys/ant021. Cf. J.F.P. Trivino. On the need of moral enhancement. A critical comment of "Unfit for the Future" of I. Persson and J. Savulescu. Resenas 2013:

${ }_{9}$ C. Zarpentine. 'The Thorny and Arduous Path of Moral Progress': Moral Psychology and Moral Enhancement. Neuroethics (2013) 6 (1): 141-53.

${ }^{10} \mathrm{~J}$. Harris, op. cit. This objection focuses on Savulescu \& Persson's suggestion that the suppression of strong negative emotional reactions would be an important element of moral bioenhancement. Drawing from Strawson, Harris notes that strong negative emotions are morally appropriate/required under certain circumstances.

${ }^{11}$ E. Fenton. The Perils of Failing to Enhance. J Med Ethics 2010. 36: 148-151, 148.

12 E. Fenton, op. cit., 148-151 highlights the moral costs associated with delaying cognitive enhancement until suitable moral enhancement is viable; see also J. Harris, op. cit., 108-110. For a critique of Fenton, see I. Persson \& J. Savulescu. The turn for ultimate harm: a reply to Fenton. J. Med. Ethics 2011: 37(7): 441-444. 
Given that Savulescu \& Persson insist that there is an "urgent need for moral enhancement" but, additionally, sufficient reason "not to support cognitive enhancement in the foreseeable future" (Op. cit: 1), the natural conclusion to draw is that we ought to promote human enhancement only in so far as what we are enhancing is moral as opposed to cognitive dispositions of human beings. This aligns naturally with the specific examples they have suggested ${ }^{13}$. However, it is a strange injunction. After all, if moral flourishing turns out to have inextricably cognitive components, then a qualified kind of moral enhancement (e.g. non-cognitive moral enhancement) would plausibly not vindicate their urgent plea for it.

There is a related worry about the underpinnings of their argument. They commit themselves to the following conditional: if $C$ is a form of cognitive enhancement, then unless $C$ is "accompanied by research into moral enhancement" (op. cit. 1), $C$ should (for reasons of risk aversion) not be pursued ${ }^{14}$. But if it turns out that certain varieties of cognitive enhancement inherently promote moral flourishing, this plausibly undercuts the argument for not pursuing them without also pursuing corresponding moral enhancement; in such cases, such a requirement would be redundant. These issues are symptoms of an underlying assumption Savulescu and Persson presuppose without question with regard to cognitive and moral enhancement--vi\%, that one form of enhancement could be in principle be prohibited while the other mandated ${ }^{15}$. A central objective of this paper will be to show why this assumption should be resisted ${ }^{16}$.

In $\$ 3$, we will argue that to aim to bring about cognitive enhancement in an individual will be to aim to bring about a kind of cognitive flourishing that, properly understood, involves certain kinds of moral improvements-a result that makes the aim of cognitive enhancement less risky than Savulescu \& Persson insist. In \4, we'll investigate the converse point- that there is a cognitive dimension that stands as an essential element of moral flourishing; accordingly, aiming to morally enhance an individual involves aiming to bring about a kind of cognitive flourishing. The sense in which the aims of cognitive and moral enhancement are interconnected stands at tension with the independence of these aims that Savulescu \& Persson rely on in their normative mandate.

Once these points are suitably clarified, we can avoid the sort of "damned if you do; damned if you don't" dilemma that Savulescu \& Persson's proposal appeared to leave us with. In light of our conclusions from $\$ \int 33-4$, we conclude in $\$ 5$ by suggesting some avenues for further research that will be sensitive to the ways in which the aims of cognitive and moral enhancement are interconnected.

\section{The moral dimension of cognitive flourishing}

\subsection{Enhancement and Flourishing: some preliminaries}

\footnotetext{
13 See, e.g., the examples they credit to T. Douglas, op. cit.

${ }^{14}$ See $\$ 5$ for a more detailed discussion.

15 Note that this assumption Savulescu and Persson are making, and which is presupposed by their recommendation for a "urgent need for moral enhancement" along with their suggestion that there is sufficient reason "not to support cognitive enhancement in the foreseeable future" (Op. cit:: 1), is an assumption regarding the independence of moral enhancement and cognitive enhancement as aims. By revealing this assumption to be problematic, we will challenge Savulescu's \& Persson's assumptions but in a way that does not involve a defence of the (obviously implausible) view that cognitive enhancement is sufficient for moral enhancement, and vice versa. Of course, 'cognitive' and 'moral' are not co-extensive terms. Thanks to an anonymous referee for requesting clarification.

16 Thanks to an anonymous referee for helpful suggestions regarding the presentation of this initial section.
} 
Savulescu \& Persson insist that the promotion of cognitive ends (e.g. by cognitive enhancement) will never, in itself, be enough to secure our moral ends; accordingly, from the fact that a subject $S$ has been cognitively enhanced, it will never follow that $S$ has been morally enhanced. ${ }^{17}$

Their argument here relies on two claims. One expresses a kind of epistemic norm-that the aim of cognitive enhancement in either traditional or non-traditional forms is the facilitation or accumulation of knowledge. The other claim is about motivational psychology - that contra Plato, knowing that $\varphi$ is the right thing to do does not by itself entail that one will in fact do $\varphi^{18}$. We agree that Plato's account of moral motivational psychology is implausible; it is the claim about knowledge we shall challenge.

First, however, some conceptual points are in order. Cognitive and moral enhancement are normative notions; the very idea of enhancement carries with it the idea of something becoming better along some parameter of evaluation--vir, its constitutive aim. 'Aim' in this constitutive sense, should be contrasted with the 'intentional' aim one adopts when one aims to bring a particular end about ${ }^{19}$. It will be worth drawing out this distinction more carefully.

For two things, $A$ and $B$, if $A$ constitutively aims at $B$, then $A$ 's aiming for $\mathrm{B}$ is part of what makes something $A$ (rather than something else)-vi\%, it is part of $A$ 's identity conditions that $A$ aims at $B ; A$ (non-constitutively) aims at $B$ when $A$ 's aiming at $B$ is not part of $A$ 's identify conditions. Obama might (non-constitutively) intentionally aim at passing a certain piece of legislation, but his aiming to do so isn't essential to his being Obama ${ }^{20}$. Conversely, we might say of beliefs, per se, that they constitutively aim at truth ${ }^{21}$; that beliefs are correct if and only if true is part of what makes an attitude a belief (as opposed to something else, e.g. a hope.) ${ }^{22}$

This distinction is relevant because we submit that what makes a given enhancement the particular kind of enhancement it is (e.g. cognitive or moral) is its constitutive $a^{23}{ }^{23}$. Put generally, for any domain of enhancement $D$, what makes enhancement $D$-enhancement (rather than, say, F-enhancement) is that D-enhancement constitutively aims at the promotion of D-flourishing.

Now, what these conceptual claims imply with respect to moral enhancement is that: moral enhancement vis-a-vis $\mathrm{S}$ is enhancement aimed at the bringing about of moral flourishing in S, whatever moral flourishing involves. Of importance for our

\footnotetext{
${ }^{17}$ Compare here with the weaker claim they are not denying: that in some cases, a cognitive enhancement would be a necessary ingredient in a moral enhancement, or vice versa. They concede this point in their debate with Harris. Thanks to an anonymous referee for stressing this point.

18 On the Humean line, one might know $f$ is the right thing to do, but lack the appropriate desires or motivations to $f$. Likewise, on the Aristotelian line, one might know that $f$ is the thing to do, and desire to $f$ but suffer from akrasia, and so not $f$.

19 Of course, this includes the aim of morally or cognitively enhancing an individual. Like the case of intentionally bringing about a belief-something that plausibly constitutively aims at truth--intentionally aiming to bring about moral or cognitive enhancement is just aiming to bring about something that is itself individuated by its constitutive aim.

20 After all, his aiming to do so is a metaphysically contingent property (not a property Obama has in all possible worlds).

${ }_{21}$ This position is held by normativists about belief. See, for example, N. Shah. 2003. How Truth Governs Belief. The Philosophical Review, 112 (4): 447-482.

${ }^{22}$ To be subject to a norm in this way does not imply that it is always better, all things considered, for a belief to be true, rather than false.

${ }^{23}$ Constitutive aims do not imply any kind of intentional act of aiming (e.g. a belief is the sort of thing that is correct if and only if true regardless of whether a given believer intends to believe truly).
} 
focus in the present section: cognitive enhancement vis-a-vis $S$ is enhancement aimed at the bringing about cognitive flourishing in $\mathrm{S}$, whatever this involves ${ }^{24}$.

Now, as was noted, Savulescu \& Persson assume that cognitive enhancement is enhancement directed at knowledge maximization ${ }^{25}$. In doing so, they implicitly identify cognitive flourishing with knowledge maximization. Although the accumulation of knowledge is surely an element of cognitive flourishing, it is far from clear that it is exhaustive of cognitive flourishing, or that it is, for that matter, its most salient aspect.

Consider, as Grimm (2012) has observed, that we make a kind of specifically cognitive gain when we move from knowledge to understanding ${ }^{26}$-from the point of view from which it is specifically our cognitive ends that matter, understanding is a better epistemic state to possess than knowledge. We desire not merely to accumulate propositional knowledge, but more over to grasp, as Miscevic (2012) puts it, "how things hang together".

This thesis about the comparative cognitive worth of understanding and knowledge is widely shared in the epistemic value literature ${ }^{27}$. An implication for our present discussion is apparent: part of what aiming to cognitively enhance an individual involves is aiming to bring about in that individual a kind of flourishing that includes understanding, not merely knowledge.

If the attainment of understanding were also a moral good and not merely a cognitive good, this could be used to defend the view that cognitive enhancement (properly construed) is less risky than Savulescu \& Persson suggest. But this avenue doesn't seem promising: as valuable as understanding is ${ }^{28}$, it isn't clear how understanding is, itself, a moral good, even if understanding can facilitate the attainment of moral goods ${ }^{29}$.

Unlike understanding, though, wisdom — as we shall see-is both an integral element of cognitive flourishing and a kind of moral good.

\subsection{Wisdom}

\subsubsection{Wisdom as constitutive of cognitive flourishing}

Though Riggs (2003) takes understanding to be a greater cognitive good than knowledge, he uses the term "wisdom" to pick out whatever is the highest cognitive $\operatorname{good}^{30}$. In fact, it is common to suggest that wisdom is the highest epistemic or cognitive good ${ }^{31}$.

So what is wisdom, and what makes it so highly prized? Answers may well depend on the type of wisdom under discussion. Wisdom has after all traditionally

${ }^{24}$ Thanks to an anonymous referee for having requested this part of the discussion be made clearer.

25 See discussion of traditional cognitive enhancement as the "transmission of knowledge" (pp. 3-4). For a sample of some other remarks in which cognitive enhancement is equated with promoting scientific knowledge, see especially pp. 7-8.

${ }^{26}$ S. Grimm. 2013.“Understanding as Knowledge of Causes." In Virtue Scientia: Essays in Philosopby of Science and Virtue Epistemology. Abrol Fairweather. Special Issue of Synthese.

27 See, for instance, D. Pritchard. 2009. "Knowledge, Understanding, and Epistemic Value." In Epistemology (Royal Institute of Philosophy Lectures). Ed. Anthony O’Hear. New York: Cambridge University Press; J. Kvanvig. 2003. The V alue of Knowledge and the Pursuit of Understanding. New York: Cambridge University Press. 28 See here, especially, J. Kvanvig, op. cit, ch. 8.

29 Put another way: understanding seems to promote moral value when it does by facilitating what is morally valuable in itself. But this much doesn't make understanding any more morally valuable than, e.g., tools/equipment that enable us to engage in activities of moral worth.

30 W. Riggs. 2003. "Understanding Virtue and the Virtue of Understanding". In Michael DePaul \& Linda Zagzebski (eds.), Intellectual Virtue: Persepectives From Ethics and Epistemology. Oxford: Oxford University Press. 31 See, for example, L. Zagzebski. 1996. Virtues of the Mind. Cambridge: Cambridge University Press. 
been understood as consisting in two distinct varieties: practical wisdom and theoretical wisdom. This distinction corresponds to Aristotle's terms phronesis and sophia, respectively. As Dennis Whitcomb (2010) notes, practical wisdom is often described as a kind of knowledge-how, where the knowledge at issue is knowledge how to live well $\hat{P}^{2}$. Theoretical wisdom, meanwhile, is often taken to pick out something more akin to deep understanding of fundamental and or significant subject matters.

Precisely delineating the distinction between practical and theoretical wisdom is a matter of longstanding controversy ${ }^{33}$. For our purposes, it suffices to note that both practical and theoretical wisdom (taken to correspond roughly to Whitcomb's distinction between knowledge-how to live well, and deep understanding) are widely taken to be essential components of cognitive flourishing. One way to appreciate the point is to consider cases in which other cognitive goods are secured, but practical and theoretical wisdom (respectively) are lacking.

SPORTS STATISTICS: Derek spends much of his time learning and memorizing sports statistics. What began as a hobby now consumes his time almost exclusively? His personal relationships suffer dramatically, his ignorance about the world (outside of baseball statistics) leaves him unable to make informed day-to-day decisions, and he finds interpersonal conversations increasingly confusing.

COLUMNIST: Matilda, knowledgeable on a range of topics in science and mathematics, wants to be accepted. She asks Susan (a well-liked syndicated columnist) for advice. Susan specifies a long list of detailed advice for living well. Matilda accepts the advice unquestioningly, never considering why any of the pieces of advice might be true, or how it fits together.

In SPORTS STATISTICS, Derek knows more propositions than most people but is nonetheless ignorant of how to live well, and it is plausibly on account of his lack of practical wisdom that his cognitive life is defective. In COLUMNIST, Matilda is both knowledgeable on a range of topics and, unlike Derek, she possesses practical wisdom: she knows how to live well because she has accepted the truths Susan has told her. Nonetheless, Matilda lacks any deep and significant understanding, and it is plausibly on account of her lack of theoretical wisdom that her cognitive life is defective. Such cases suggest that wisdom, in both its practical and theoretical guises, is an essential feature of cognitive flourishing.

\subsubsection{Wisdom as a moral good}

What is the relationship between wisdom and moral flourishing? Rather than claiming that wisdom, like knowledge, is merely an instrument that can be used in the service of achieving goods that are themselves of moral worth--a claim Savulescu \& Persson would be happy to grant--we want to suggest that wisdom itself is a moral good. Specifically, whenever one's wisdom is enhanced, so is one's moral standing.

There are several ways to make this point. Regarding practical wisdom, the argument is simple: moral flourishing consists in living well, and while knowing how to live well (vi\%, possessing practical wisdom) does not entail that one actually lives

\footnotetext{
32 D. Whitcomb. 2010. “Understanding” In the Routledge Companion to Epistemology, Eds. S. Bernecker \& D. Pritchard.

33 For recent survery, see J. Baehr. 2012. “Two Types of Wisdom.” Acta Analytica 27: 81-97.
} 
well, it is a necessary element for doing so. An individual ignorant of what to do to live well will not do so, even if she has the desire to. Moreover, a common position on moral virtue is that practical wisdom is an essential component of rightly exercising moral virtue ${ }^{34}$. Without practical wisdom, then, one will de facto fail to possess moral virtue; and, moreover, one would not know what ends to bring about, even if one desires what a virtuous person desires. Living well involves practical wisdom.

With theoretical wisdom, the story is a bit different. As Whitcomb suggests, practical wisdom is most closely associated with the epistemic state of knowledge (or, knowledge-how), while theoretical wisdom is most closely associated with a certain kind of understanding. As Garrett (1996) puts it, wisdom "is that understanding ... essential to living the best life ${ }^{35}$." This aligns closely with Nozick's (1989) view ${ }^{36}$. In each case, the understanding characteristic of wisdom concerns a subject matter that is morally relevant.

There are at least three reasons for thinking that theoretical wisdom, as an epistemic state construed as a kind of deep understanding of morally relevant subject matter, has moral (and not merely cognitive) value.

Firstly, as Whitcomb notes, "every writer about wisdom that I know of

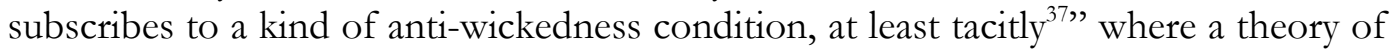
wisdom (practical or theoretical) satisfies such a condition only if consistent with the observation that [unlike knowledge and understanding] wisdom and wickedness are taken to be incompatible ${ }^{38}$. But, if wisdom, by its nature, precludes wickedness, then the promotion of wisdom itself increases one's moral flourishing.

Secondly, following Baehr (2012), theoretical wisdom is plausibly a kind of element of living well rather than merely a means to it, given the tight connections between theoretical and practical wisdom. As Baehr puts the point:

It is entirely reasonable to think of deep explanatory understanding of epistemically significant subject matters as among the ends about which a person of practical wisdom might deliberate and make efforts to bring about... the practically wise person's understanding of moral and other normative subject matters apparently will involve an element of the theoretically wise person's grasp of the same ${ }^{39}$.

Thirdly, on a virtue-theoretic line ${ }^{40}$ we have further reason to suppose wisdom enhances moral standing; on such a line, promoting wisdom cultivates in an individual not only other intellectual virtues, but also moral virtues (e.g. honesty, temperance, humility). Accordingly, it is no surprise that, as Isacc Asimov has remarked, "The saddest aspect of life right now is that science gathers knowledge faster than society gathers wisdom ${ }^{41}$."

\footnotetext{
${ }^{34}$ This is the classical Aristotelian line concerning the relationship between phronesis and the virtues.

${ }^{35}$ R. Garret. 1996. "Three Definitions of Wisdom." In Knowledge, Teaching and Wisdom, ed. K. Lehrer, Philosophical Studies Series Volume 67, pp 221-232

${ }^{36}$ Nozick views wisdom as a kind of knowledge or understanding "you need... in order to live well and cope with the central problems and avoid the dangers in the predicament(s) human beings find themselves in" (Nozick 1989: 267-268). Cited also in Whitcomb (2010, op cit., 8).

37 Whitcomb, Op. cit., 18.

38 Whitcomb himself demurs on this point.

39 J. Baehr. 2012. "Two Types of Wisdom.” Acta Analytica 27: 91

40 See e.g. R. Hursthouse. 2012. Virtue Ethics. Stanford Encyclopedia of Philosophy; Fall 2012 Edition, who notes it is common to hold that that lacking practical wisdom is sufficient for failing to possess the virtues.

41 Asimov and Jason A. Shulman's "Isaac Asimov's Book of Science and Nature Questions" (New York: Weidenfeld \& Nicolson, 1988), p. 281.
} 


\section{The cognitive dimension of moral flourishing}

Just as there is a moral dimension to cognitive flourishing, there is a cognitive dimension to moral flourishing. In this section, we will take a closer look at the connection between emotions and moral flourishing, and submit that since moral flourishing involves an essential cognitive component then (contra Savulescu and Persson) it no longer makes sense to claim that we can aim to morally enhance by trying to make better features that exclude cognitive features. More generally, we call into question the presumption that moral enhancement is achievable out with cognitive enhancement.

\subsection{Emotions and moral flourishing}

There are good reasons to suppose there is a connection between emotions and moral flourishing; for example, consider Aristotle's famous distinction between virtue and continence - the feelings of satisfaction involved in being truly virtuous suggest just such an important link between one's moral character and one's emotions. When exploring this apparent connection in more depth, it makes sense to start by looking at which emotions might most likely be essential. While there are many possible candidates, we can for the sake of simplicity focus on the emotions that Savulescu and Persson discuss in their treatment of moral enhancement. On their preferred view, at the core of our moral dispositions lies a disposition to altruism. They define altruism (p. 12) as '[sympathizing] with other beings, [wanting] their lives to go well rather than badly for their own sakes', and note that 'few would deny that this disposition is central to morality.'

We agree-for example, in addition to being widely prescribed by a range of different religious and featuring in Hume's work on sympathy ${ }^{42}$, the importance of responding appropriately to the suffering of others is highlighted in Aristotle's view of compassion (and in the more modern account of compassion offered by Nussbaum (2001) ${ }^{43}$, to which we will return shortly).

When looking at the emotions involved in altruism 44 , Savulescu \& Persson suggest that a large part of altruism is, for example, feeling sad when others are wronged, and happy when life goes well for others. In addition, they make much of the dispositions from which our sense of justice or fairness arises. They hold that the most basic of the dispositions related to justice and fairness are the so-called "tit-fortat" dispositions ${ }^{45}$, for instance: feeling grateful or angry depending on whether a favour is granted or a harm is done, and more sophisticated responses such as feeling remorseful and guilty if you have wronged another without good reason, feeling pride or shame if you are more or less successful than others at returning favours, feeling admiration or contempt for others who are successful or unsuccessful in these respects, and feeling forgiving when you realize that someone is remorseful or blameless for a particular wrong. Savulescu \& Persson note that if they are right to

\footnotetext{
${ }^{42}$ e.g. D. Hume. 2000. A Treatise of Human Nature (Oxford Philosophical Texts), David Fate Norton and Mary J. Norton (eds.), Oxford, Clarendon Press. In particular, Hume articulated the nature of moral judgments in terms of expressing our feelings of approval and disapproval, connected to outcomes that are advantageous or disadvantageous, and where positive appraisals of states of affairs that benefit others besides ourselves are explained with reference to our capacities for sympathy.

${ }^{43}$ Martha Nussbaum, "Upheavals of Thought: The Intelligence of Emotions" (Cambridge: Cambridge University Press, 2001).

${ }^{44}$ For work on the biological background of altruism, see Sober, E. and Wilson D. S. (1998) Unto Others (Cambridge MA: Harvard U. P.

45 See e.g. Wright, R (1994) The Moral Animal, (New York: Pantheon)
} 
think that the dispositions of altruism and justice are central to our morality, 'moral enhancement will consist in strengthening our altruism and making us just or fair, i.e., properly grateful, angry, forgiving, etc.' (p. 13).

It is obvious, then, that Savulescu and Persson think that the aforementioned types of emotions are just the sort that are essential to moral flourishing ${ }^{46}$, and it is not hard to see why this is a sensible view ${ }^{47}$.

\subsection{Emotions as cognitive}

Now, given that some emotions are apparently essential to moral flourishing, consider that it is widely held that emotions involve a cognitive element. As Cates (2003) puts it, it is common to hold that emotions 'involve thought, judgment, and evaluation' and further, that 'most scholars who study the emotions also agree that it is partly because the emotions have some relationship to thoughts-especially to beliefs and evaluative judgments- that they are appropriately subject to critical reflection and moral evaluation.' (Cates 2003: 326).

Importantly, strong cognitivist theories of emotions insist that emotions can be characterized in terms of their related cognitive processes and at least some as necessarily involving propositional attitudes. For example, emotions like anger and envy require believing that, say, someone else has done/possessed something in particular, and (in the former case) perhaps believing something about human dignity being lost or threatened ${ }^{48}$. Nussbaum (2001) advances a strong cognitivist line, according to which emotions just are thoughts or cognitions; this can be contrasted with the more moderate view that emotions merely include an essential cognitive component. For example, Nussbaum's view holds that being angry at someone just is judging that they have wronged you. She submits that emotion-cognitions are 'forms of evaluative judgment that ascribe to certain things and persons outside a person's own control great importance for the person's own flourishing' (p. 22). In brief, her argument for why emotions do not necessarily involve anything other than cognitions ${ }^{49}$ (2001: 56-7) is that while some emotions may include one or more 'nonthinking movements' such as trembling hands, there is not a consistent correlation between particular movements and particular emotions (unlike the link between particular emotions and particular thoughts).

Along with Nussbaum, Solomon (1980) ${ }^{50}$, and Neu${ }^{51}$ (2000) also identify emotions with judgements, while other strong cognitivist views feature subtle differences-for example, Broad (1971) ${ }^{52}$ and Lyons (1980) $)^{53}$ characterize emotions as affect-laden judgements, and Marks (1982) $)^{54}$ endorses that view that they are sets

\footnotetext{
${ }^{46}$ Savulescu \& Persson also discuss less basic issues relating to emotion and enhancement, including racism, anger impediment and the notion of what they call "executive virtue".

${ }^{47}$ For example, it is difficult to imagine an ideal moral agent who does not experience gratitude upon receipt of a significant favour, or respond negatively to unfair suffering visited on another.

48 For instance, as will be the case when one's anger is provoked by a perceived humiliation or insult.

${ }^{49}$ Nussbaum takes 'cognitive' to mean 'nothing more than concerned with receiving and processing information' (Op. cit.: 23).

50 Robert Solomon, "Emotions and Choice." In Explaining Emotions. Ed. Amelie Rorty. Los Angeles: University of California Press, 251-81.

51 Jerome Neu, "A Tear is an Intellectual Thing: the Meaning of Emotions" (Oxford, New York: Oxford University Press, 2001).

52 C.D. Broad, "Emotion and Sentiment." In Critical Essays in Moral Essay. Ed. ????. London: Allen and Unwin.

53 William Lyons, "Emotion” (Cambridge: Cambridge University Press, 1980)

${ }^{54}$ J. Marks. 1982. A Theory of Emotions. Philosophical Studies, 42 (4): 227-242
} 
of beliefs and desires. Of course, these cognitivist views are criticized ${ }^{55}$. It suffices for our purposes to register the position as a widely held view that may come in many plausible variations that are taken seriously in the debate about the nature of emotions.

At this point, an obvious threat to Savulescu and Persson's neat division between the moral and the cognitive emerges. If emotions are essential for moral flourishing and emotions are cognitive in nature, perhaps some of emotions essential to moral flourishing can be viewed as cognitive. As it turns out, many of the emotions that we suggested as necessary for moral flourishing (and on which Savulescu and Persson focus) fit well with the view of emotions as judgements ${ }^{56}$. For example, as Savulescu and Persson describe, gratitude could be the judgement that a favour has been done, and admiration the judgement that someone has done something laudable. Regarding the disposition to altruism more broadly, Nussbaum presents a detailed account of the cognitive structure of compassion.

In sum, if it turns out that emotions that are (essentially, or even partly ${ }^{57}$ ) cognitive in nature are essential to moral flourishing, then part of what it is to morally flourish is inextricably cognitive, and the notion of moral enhancement without cognitive enhancement no longer seems to make sense ${ }^{58}$.

\section{Beyond 'Cognitive' and 'Moral' Enhancement}

\subsection{A closer look at Savulescu and Persson's proposal}

The crude conceptual distinction Savulescu \& Persson draw between the cognitive and the moral is, granted, likely be sufficient for a wide range of commonplace purposes. However, when the goal is to employ such a distinction in the service of deciding which types of enhancement should be urgently pursued or discouraged, the framework is insufficient for guiding action.

For instance, Savulescu \& Persson insist cognitive enhancement must not be pursued out with corresponding moral enhancement, but what counts as sufficiently pursuing corresponding moral enhancement? For example, into what category would they place cognitive enhancements that are accompanied by research into how (or to what extent) those enhancements could also involve moral enhancements?

Perhaps they would be willing to license cognitive enhancement only if large, well-funded projects prioritize and develop moral enhancements that are at least as (or, perhaps, significantly more) effective as the corresponding cognitive enhancement is dangerous. This has initial promise, though it's not clear how any

\footnotetext{
${ }^{55}$ Lyons (1980), Goldie (2000) and Elster 2003) claim cognitivism implausibly reduces emotional rationality to the rationality of standard propositional attitudes. Potential lines of defense (e.g. Peacocke 2001, Goldie 2000, Charland 2002 and Tappolet 2003) include (i) arguing that the propositional content of emotion is not like that of belief (comparing it with the possible propositional content of perceptions), and (ii) claiming that the content of both emotions and perceptions might not be limited to propositional content. Recalcitrant emotions are also often discussed (e.g. Stocker 1992; Brady 2009). However, there are also various attempts to defend strong cognitivism against criticisms. See e.g. Wollheim 1999, Peacocke 2001, Goldie 2000, Charland 2002, and Tappolet 2003.

56 Or as involving a judgment component.

57 It is important to note that although we discuss the strong view (which is problematic for Savulescu \& Persson insofar as they rule it out ex ante), the more moderate view of emotions (according to which emotions involve cognitions) would also be problematic because the cognitive element is nonetheless essential to all emotions.

58 We note that there are other interesting ways to press the line that there is a cognitive dimension to moral flourishing. For example, Milgram (2005) Ethics Done Right: Practical Reasoning as a Foundation for Moral Theory. (New York: Cambridge University Press, 2005) submits that practical reasoning is essential to moral flourishing.
} 
potential positive consequences could play such an offsetting role on their proposal. Moreover, given that Savulescu \& Persson insist it might well be morally mandatory to pursue moral enhancement (while forbidden to pursue merely cognitive enhancement), it is crucial that we ask: it is the case that any type of enhancement that substantially influences morality is therefore a moral enhancement? What is a moral enhancement?

Savulescu \& Persson's heavy reliance on the messy business of distinguishing between moral and cognitive enhancement is made even more problematic by the fact that the very concept of cognition is complex-some critics of the cognitive view of emotions (e.g. Power \& Dalgleish (2008), Debes (2009) ${ }^{59}$ ) think that such confusions infect any attempt to discuss anything in the cognitive domain. Indeed, to the extent that 'cognition' is a vague term, there will be an action-guiding problem for any proposal making essential reference to a distinction between cognitive and moral enhancement. All the more reason, then, to move beyond reliance on the terms 'moral' and 'cognitive' when deciding which enhancements should be pursued.

\subsection{Beyond 'cognitive' and 'moral' enbancement}

In spite of the fact that Savulescu \& Persson's proposal is not appropriately sensitive to the connections between the aims of cognitive and moral enhancement, we agree with the core thought that it is important to improve the moral character of humanity and to be careful about the types of purely intellectual advancements made in the absence of corresponding moral advancements. In light of the objections developed in $\$ \int 3-4$, we are concerned that their approach to enhancement may end up being unproductive with respect to the end of most effectively improving the moral character of humanity (by, for example, quickly dismissing enhancements that 'look too cognitive' or failing to create the best advancements towards moral flourishing for fear of incorporating too many cognitive enhancements).

One commonsense alterative approach to potential enhancements is to consider them out with any essential reference to a moral/cognitive conceptual dichotomy. For example, for any enhancement E, we suggest considering the proposed goal of $\mathrm{E}$ (e.g. to improve trait $\mathrm{T}$ ) and evaluating this in a wide range of ways. How successful is E likely to be at improving T? What other effects will it likely have in addition to improving T? Will it plausibly encourage people to treat each other better, or worse, and in what circumstances? Does it carry with it an increased risk of creating or utilising destructive technology? These are just some examples of appropriate questions to ask in place of whether the enhancement is moral or cognitive. Our suggestion aligns with a more general point suggested in work by Brownsword \& Somsen (2009) ${ }^{60}$. As Brownsword suggests, it is "unclear ... whether an 'across-the-board' set of principles for the regulation of human enhancement is appropriate. ${ }^{61 "}$

It should also be noted that the ethics of human enhancement features issues that, in practice, must be approached at least in part in the context of governance.

\footnotetext{
${ }^{59}$ R. Debes 2009. "Neither Here Nor There: The Cognitive Nature of Emotion." Philosophical Studies 146(1): 1-27; M. Power and T. Dalgleish 2008. Cognition and Emotion : From Order to Disorder, 2nd edition, Hove: Psychology Press.

${ }^{60}$ R. Brownsword, , and H. Somsen (2009) Law, Innovation and Technology: Before We Fast Forward A Forum for Debate, Law, Innovation and Technology, 1, 1-73. Thanks to an anonymous referee for drawing our attention to this paper.

${ }^{61}$ Cited also in Capps, et. al (op. cit. 257).
} 
And, as Capps, et. al. (2012) ${ }^{62}$, notes, the questions that arise in this context will often be interdisciplinary. As Chadwick ${ }^{63}$ has mentioned, a sample of such questions include: "1) What is the likely impact on existing inequalities?; 2) What is the likely impact on choice, local and global?; and 3) What is the likely impact on vulnerable groups?" Plausibly, assessing traits in light of these governance-based questions will (as with the kinds of considerations previously mentioned) be drawing us away from the moral/cognitive dichotomy.

Similarly, consider a problem-centred proposal. For some problematic threat $\mathrm{P}$, we might consider a range of specific traits and assess: which traits are most causally responsible for $\mathrm{P}$, and what are the risks of attempting to modify these traits? Likewise, regardless of which traits are responsible for $\mathrm{P}$, are there other traits such that their modification or enhancement will raise the likelihood that $\mathrm{P}$ will be mitigated? What are the risks of attempting to enhance these traits? Again, the relevant questions do not rely on a distinction between moral and cognitive enhancement.

Both the enhancement-centred and problem-centred approaches we've outlined here are compatible with the more general scientific approach to risk decision making: cost-benefit analysis (CBA). The general idea would be to treat the decision of whether and what kinds of enhancements to pursue in light of perceived risks (including the risks motivating Savulescu \& Persson's project) as a special case of a decision under risk, more generally. On such a proposal we can-without drawing moral and cognitive classifications-focus on three central questions. As Hansson (2007) ${ }^{64}$ claims, the relevant philosophical issues that arise when one attempts to apply a CBA in risk decision making are: firstly, how do we frame the relevant alternatives? For example, what specific forms of enhancement, or problems, are relevant to the decision? Secondly, how do we characterize the possible outcomes for each alternative? Thirdly, how do we assign values to the alternatives? In focusing on these questions, we sidestep entirely the "damned if you do, damned if you don't" scenario that arises once we try to implement the kind of injunction proposed by Savulescu \& Persson. Of course, the outline of a proposal we've sketched here is incomplete, and cost-benefit analysis is just one potential avenue for approaching the enhancement debate. As critics of CBA will be quick to point out, the kind of unknown risks that may well feature in enhancement contexts might equally motivate the application of a kind of precautionary principle of the sort that features in debates in environmental ethics ${ }^{65}$. Again, we are open to such proposals; to reiterate: is beyond our aim here to defend any particular positive proposal. Our main objective has been to make it clear that the very risks motivating Savulescu \& Persson to want to forbid cognitive enhancement and mandate moral enhancement are such that-if we are to take them seriously-will require that we leave talk of cognitive and moral enhancement behind.

\footnotetext{
${ }^{62}$ B.J. Capps, R. Ter Meulen, R. \& L. Nielson.. 2012. Human Enhancement Technologies: Understanding Governance, Policies and Regulatory Structures in the Global Context. Asian Bioethics Review, 4(4), 251-258.

Thanks to an anonymous referee for bringing this paper to our attention.

${ }^{63}$ Ibid. p. 256.

${ }^{64}$ S.O. Hansson. 2007. Philosophical problems in cost-benefit analysis.Economics and Philosophy, 23(02), 163183.

${ }^{65}$ For a defense of the precautionary principle against recent charges, see Sandin, P., Peterson, M., Hansson, S. O., Rudén, C., \& Juthe, A. (2002). Five charges against the precautionary principle. Journal of Risk Research, 5(4), 287-299.
} 